
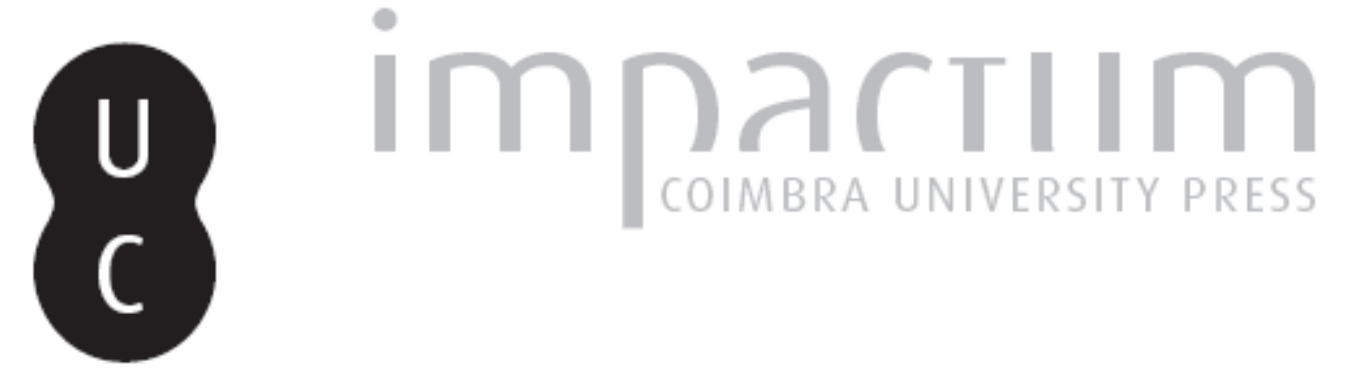

\title{
A mulher e a Pré-História: alguns apontamentos para questionar a tradição e a tradução da mulher-mãe e mulher-deusa na Arqueologia pré-histórica
}
Autor(es):
Vale, Ana

Publicado por: Faculdade de Letras da Universidade de Coimbra

URL persistente:

URI:http://hdl.handle.net/10316.2/39124

DOI:

DOI:http://dx.doi.org/10.14195/1647-8657_54_1

Accessed : $\quad$ 26-Apr-2023 00:11:05

A navegação consulta e descarregamento dos títulos inseridos nas Bibliotecas Digitais UC Digitalis, UC Pombalina e UC Impactum, pressupõem a aceitação plena e sem reservas dos Termos e Condições de Uso destas Bibliotecas Digitais, disponíveis em https://digitalis.uc.pt/pt-pt/termos.

Conforme exposto nos referidos Termos e Condições de Uso, o descarregamento de títulos de acesso restrito requer uma licença válida de autorização devendo o utilizador aceder ao(s) documento(s) a partir de um endereço de IP da instituição detentora da supramencionada licença.

Ao utilizador é apenas permitido o descarregamento para uso pessoal, pelo que o emprego do(s) título(s) descarregado(s) para outro fim, designadamente comercial, carece de autorização do respetivo autor ou editor da obra.

Na medida em que todas as obras da UC Digitalis se encontram protegidas pelo Código do Direito de Autor e Direitos Conexos e demais legislação aplicável, toda a cópia, parcial ou total, deste documento, nos casos em que é legalmente admitida, deverá conter ou fazer-se acompanhar por este aviso.

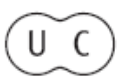


CONIMBRIGA

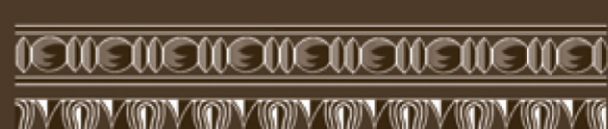

WN N N N

INSTITUTO DE ARQUEOLOGIA

VOLUME LIV • 2015

FACULDADE DE LETRAS 
Ana VAle

Centro de Estudos em Arqueologia, Artes e Ciências do Património. Departamento de Ciências e Técnicas do Património. Faculdade de Letras da Universidade do Porto ana.m.vale@gmail.com

A MULHER E A PRÉ-HISTÓRIA. ALGUNS APONTAMENTOS PARA QUESTIONAR A TRADIÇÃO E A TRADUÇÃO DA MULHER-MÃE E MULHER-DEUSA NA ARQUEOLOGIA PRÉ-HISTÓRICA

THE WOMAN AND PREHISTORY. SOME QUESTIONS ON THE TRADITION AND TRANSLATION OF THE WOMAN-MOTHER AND WOMAN-GODDESS IN PREHISTORIC ARCHAEOLOGY "Conimbriga" LIV (2015) p. 5-25

http://dx.doi.org/10.14195/1647-8657 54_1

RESUmo: A construção dos discursos explicativos acerca da Pré-história Recente pela Arqueologia tradicional assenta num conjunto de preconceitos dados como naturais (naturalizados) pela ordem patriarcal do mundo ocidental. Importa perguntar: será possível traduzir objetos em atividades e associar cada atividade a um sexo? Após décadas de crítica feminista e estudos de género, poderá a Arqueologia portuguesa continuar a perpetuar discursos de matriz androcêntrica? Como resgatar a mulher ao silêncio e às margens do discurso mas sem cair na tentação de reproduzir a sua imagem estereotipada (como mãe e deusa) no passado? Como construir um passado que fale de seres humanos?

Palavras-CHave: Pré-História Recente; Mulher/Homem; Ser Humano

ABSTRACT: The traditional construction of narratives about recent Prehistory is founded on a set of preconceptions taken as natural by

Conimbriga, 54 (2015) 5-25 
the patriarchal order of the western world. Is it possible to translate objects into activities, and associate each activity with a specific sex? After decades of feminist critic and gender studies, can Portuguese archaeology continue to perpetuate androcentric discourses? How can women be rescued from silence and from the margins of past discourses without falling to the temptation of reproducing the stereotypical image of women in the past (as mother and goddess), and how can a past that talks about human beings (instead of males and females) be constructed?

KeYwords: Recent Prehistory; Woman/Man; Human Being 


\section{A MULHER E A PRÉ-HISTÓRIA. \\ ALGUNS APONTAMENTOS PARA QUESTIONAR \\ A TRADIÇÃO E A TRADUÇÃO DA MULHER-MÃE E MULHER-DEUSA NA ARQUEOLOGIA PRÉ-HISTÓRICA}

\section{Introdução}

Este texto procura falar acerca das múltiplas e ambíguas relações entre a Mulher e a Pré-história, sobretudo acerca das representações da mulher no passado, da mulher que é e se tornou mãe e deusa; personagens inspiradoras, protetoras, vitais porque ligadas inevitavelmente à fertilidade do ventre e da terra, mas passivas no devir histórico. Procura também equacionar as complexas relações entre ser-se mulher hoje e a construção do passado, indissociável da reflexão acerca do próprio enunciado - ser-se mulher.

"Foram duas das minhas aventuras da minha vida profissional. A primeira - matar o Anjo do Lar - acho que resolvi. Ela morreu. Mas a segunda, dizer a verdade acerca das minhas próprias experiências enquanto corpo, acho que não a resolvi." (WoOLF 2014 [1931]:195)

Virginia Woolf foi capaz de matar o Anjo do Lar, o fantasma que a atormentava, que the sussurrava ao ouvido como falar, escrever, andar, que lhe dizia como ser mulher (do lar) no início do século XX. Virginia Woolf matou-a para poder trabalhar, para poder ser (mulher). Mas se Woolf conseguiu matar o Anjo do Lar, permaneceu na confusão da condição/representação do seu próprio corpo, um corpo do sexo feminino que devia obedecer a normas de conduta específicas, que se pensa(va)m naturais. A representação do corpo e os papéis que cada corpo deve perfomatizar de acordo com os discursos vigentes, as aprendizagens e expectativas de cada corpo hoje, encontram-se em debate 
na construção de "passados". Na construção de discursos acerca de possíveis passados onde inevitavelmente projetamos as representações dos nossos próprios corpos, mas que não podem validar as representações de hoje. Como Bourdieu salientou, as próprias diferenças visíveis "entre os órgãos sexuais masculino e feminino são uma construção social que tem a sua génese nos princípios da divisão da razão androcêntrica, baseada, por sua vez, na divisão dos estatutos sociais atribuídos ao homem e à mulher." (Bourdieu 2013: 30). Como escreve a Arqueologia a ambiguidade do que se crê natural e atemporal?

As distinções/divisões entre sexos estruturam a ordem social. Nas narrativas acerca da Pré-história, o corpo feminino, que se imagina quase sempre frágil, é remetido à penumbra da casa, às atividades domésticas, enquanto as representações de atributos femininos são considerados como representações do sagrado. O homem, de corpo forte, é capaz de desenvolver as atividades exteriores, públicas e fisicamente mais exigentes. A pretensa neutralidade deste discurso baseado na pretensa naturalidade das diferenças biológicas entre sexos, insere-se em um poderoso discurso ideológico androcêntrico. É possível esta leitura a partir dos materiais (arqueológicos)? Que mulher (e que homem) transpomos para o passado? Será possível falar unicamente de seres humanos?

\section{As representações de mulheres na Pré-história}

Neste texto referimo-nos especificamente às representações da mulher datadas do III milénio AC, da mulher do tradicional Calcolítico, que encontra reservado a si um conjunto de funções, mais ou menos explícitas, nas explicações acerca sobretudo dos chamados "povoados fortificados". A mulher, remetida aqui ao espaço doméstico, é responsável pelas tarefas de manutenção da comunidade - prepara os alimentos, tece, cuida e trata do espaço intramuros. Mas a representação do corpo feminino é também lido como representação do sagrado; as placas de xisto gravadas do III milénio AC são associadas a representações da "Deusa Mãe" (e.g. GonçALVES 2004), onde o sexo é sugerido pelo desenho de triângulos, preenchidos ou não, e onde se podem ler outros atributos femininos, como "longos cabelos ziguezagueantes" (Gomes 2005: 178). O culto da Deusa encontra-se, segundo a Arqueologia tradicional, implícito em outros objetos, como nos chamados 
ídolos-falange (CARDOSo 1995), onde os triângulos, as linhas ziguezagueantes e outros atributos, tidos como representações de características de corpos femininos, os ligam a cultos de fertilidade. O corpo feminino alberga o sagrado e o profano, ambivalente na representação, mas ligado inevitavelmente à maternidade, à reprodução do homem e do que brota da terra. A mulher, como mãe, é aquela que alimenta nos primeiros meses/anos de vida, mas também aquela que forma durante os primeiros anos aqueles que um dia serão homens.

Os homens que serão encarregues da proteção da comunidade, sobretudo das mulheres e das crianças ainda a cargo destas. Serão também estes os homens a manusear o arco e a flecha na caça. A prática da metalurgia do cobre, ainda que não seja dito explicitamente em texto que estava reservada a homens, é ilustrada nas imagens que nos são transmitidas, e sobretudo aquelas que são transmitidas ao grande público, pelo homem metalúrgico. E se, por um lado o Calcolítico peninsular carrega no nome a metalurgia do cobre, é, ainda, caracterizado pela feitura de recintos murados no topo de colinas, recintos interpretados pela Arqueologia tradicional como recintos fortificados. A construção destas muralhas parece também associar-se às atividades masculinas, não se enquadrando nas tarefas levadas a cabo pelos elementos femininos.

Assim, aos elementos masculinos parecem ser atribuídas as atividades mais perigosas, e também as mais criativas. O homem guerreiro, o homem caçador, o homem metalúrgico, o homem construtor/arquiteto. As ações protagonizadas pelos elementos masculinos das comunidades que habitaram os recintos murados peninsulares resumem a própria definição de Calcolítico. Os lugares de destaque e poder na explicação e definição dos recintos murados estão assim ocupados sobretudo por homens. A mulher desempenha as tarefas de fundo, como cozinhar, limpar, providenciar agasalho, assegurando ao homem a possibilidade de arriscar, inovar, transformar e criar.

Este discurso diz também acerca de um tipo de masculinidade naturalizado pela sociedade burguesa. Outras formas de ser-se homem são anuladas. Os estereótipos com as quais se representam as mulheres - dona de casa, mãe e deusa - vêem-se ao espelho nos estereótipos masculinos - protetor, guerreiro, caçador. Se é verdade que os discursos androcêntricos conectaram a mulher com atividades passivas relegando-a à invisibilidade, também silenciou outras masculinidades ao pretender falar com a voz de um tipo masculino particular (construído 
pelo mundo moderno ocidental), pressupondo uma masculinidade hegemónica (seguindo Almeida 2003). Este tipo de "homem", descrito como racional, responsável pelas inovações tecnológicas, a quem é reconhecida uma identidade individual (e não tanto por pertença ao grupo), insere-se no discurso patriarcal do mundo moderno ocidental que procura no passado a legitimação do discurso dominante (HERNANDO 2013).

A ligação das mulheres às tarefas domésticas e dos homens às atividades públicas, transformativas e inovadoras é lida como natural porque também naturalizada ao longo do tempo. Veja-se a forma como a Pré-história recente é dita num manual escolar do $7^{\circ}$ ano de escolaridade: "Às mulheres cabiam os cuidados com os filhos e as atividades artesanais, como a olaria e a tecelagem. Os homens responsabilizavam-se pelo trabalho do campo, pela pesca, caça, pastorícia e pela proteção de todos os bens do aldeamento." (CIRNE e HenRiQues 2012: 20). Mas é sobretudo na comunicação com o grande público, na transmissão da informação "arqueológica" (materializada em guias de sítios arqueológicos, panfletos de divulgação, ilustrações em museus...) que os preconceitos de género são mais gritantes, mais fáceis de identificar, apontar e analisar, e transmitidos como naturais e inevitáveis na explicação do passado (VALE 2010). Mas parecem passar em silêncio... É fácil encontrar representações de mulheres junto dos espaços domésticos, envolvidas na preparação dos alimentos. As mulheres são também sempre desenhadas próximas dos ambientes familiares e protegidos, como a casa ou o povoado. Os materiais aos quais estão normalmente ligadas materializam a tradição, a tradição das atividades, do dia-a-dia, do quotidiano. Por outro lado, a representação do corpo feminino é conectado com a Deusa Mãe, exibindo os atributos físicos lidos como símbolos de fertilidade. A mulher deusa e a mulher mãe. Em que contextos arqueológicos se baseiam estas representações?

\subsection{O corpo humano e representações antropomórficas durante o III milénio AC em território português}

De forma muito sumária, e conscientes da impossibilidade de mencionar todos os trabalhos publicados para este exercício, percorremos alguns contextos (funerários e de arte rupestre) e artefactos arqueológicos (figuras antropomórficas) de forma a questionar as repre- 
sentações tradicionais de homem e mulher no III milénio AC, especificamente em relação com a construção e uso de recintos (murados e de fossos), em contexto português.

Nos enterramentos conectados com os recintos murados e os recintos de fossos não se verifica qualquer diferenciação entre sexo ou entre classe etária (apenas é salientado para o caso do Zambujal a possibilidade de enterramento de crianças dentro do recinto, Kunst et al. 2014). Os enterramentos são geralmente colectivos e é raro a identificação de contextos primários; os ossos humanos parecem ter sido manipulados, enquanto fragmentos (sem relação com o indivíduo ao qual pertenceram, sem afinidades de género?). Estes corpos, alguns desarticulados, encontram-se, na maioria dos casos e por razões diversas, sem associação direta com o espólio funerário presente na estrutura de enterramento (e.g. Valera et al. 2014 ou Jorge et al. 1998-99; o mesmo parece passar-se em outros contextos do III milénio AC, e.g. Baptista 2015).

Em Castelo Velho de Freixo de Numão, a reunião de fragmentos de ossos humanos, fragmentos de ossos de animais, fragmentos cerâmicos e pesos de tear, no interior de uma estrutura de base pétrea, foi interpretada como deposição de fragmentos de "coisas" possivelmente manipuladas e integradas em outros circuitos/ações prévias à sua deposição final neste contexto (JORGE 2014). Nesta estrutura estão presentes parte do esqueleto de um indivíduo do sexo feminino (com idade entre 18 e 20 anos) e fragmentos de ossos correspondentes a pelo menos 9 indivíduos (de ambos os sexos e pertencentes a crianças, jovens e jovens adultos). Susana Jorge não define este contexto enquanto enterramento mas como deposição (em momentos formalizados) de "coisas" fragmentadas, que incluem ossos humanos. Notamos, também, que a deposição se parece construir em torno do fragmento do esqueleto do indivíduo do sexo feminino, cuja parte dorsal se encontra em conexão anatómica, a que se associam fragmentos de ossos de outros indivíduos, e, segundo a autora, com o mesmo "estatuto", fragmentos cerâmicos, fragmentos de ossos de animais e pesos de tear ${ }^{1}$ (ibid.).

${ }^{1} \mathrm{O}$ estudo desta estrutura ainda se encontra em curso, e pretende, à luz das novas problemáticas suscitadas por Susana Oliveira Jorge (2014) e no contexto da Arqueologia do Género, pensar a relação entre fragmentos de esqueletos humanos e fragmentos de outras materialidades, nunca perdendo de vista a sua possível comparação com contextos semelhantes presentes em sítios formalmente similares.

Conimbriga, 54 (2015) 5-25 
$\mathrm{Na}$ maioria dos contextos funerários em território português não é assim possível articular esqueleto e espólio, mas mesmo que tal relação se pudesse estabelecer, o espólio não pode, por si só, ser tido como indicador de diferenciação de género ou social, pois os rituais de enterramento podem envolver a escolha de certos objetos não diferenciadores dos cadáveres, ou certas comunidades podem optar pela completa ausência de artefactos a acompanhar aquele que morreu. Nos textos acerca dos enterramentos em (ou em relação com os) recintos a discussão acerca das possíveis diferenças entre sexos não é praticamente enunciada, excepto no caso de Bela Vista 5, Beja, (enterramento integrado no chamado horizonte de Ferradeira) no qual um indivíduo feminino se fazia acompanhar por três recipientes cerâmicos e dois objetos metálicos: um punção (em um dos vasos) e uma ponta Palmela; Valera ressalva "cabe ainda sublinhar a natureza da associação deste espólio votivo, nomeadamente com a presença de uma ponta Palmela, a uma mulher adulta, facto revelador que as armas não são exclusivamente assocadas a elementos masculinos." (2014: 45).

Em algumas estatuetas, figurinhas ou placas antropomórficas o sexo biológico encontra-se explícito. Outras, no entanto, ainda que de contorno antropomórfico, não exibem qualquer referência ao sexo. A Arqueologia tradicional tem lido nas representações antropomórficas inscritas em placas de xisto ou em outros suportes como falanges de animais, atributos conectados com a divindade feminina que seria adorada neste período (e.g. CARDoso 1995; Gomes 2005; GonÇALVES 2004). O desenho, por exemplo, de triângulos e linhas em ziguezague é interpretado como atributos do corpo feminino, neste caso, como representativos do sexo ou do cabelo (comprido).

Sugerir que as representações do corpo do sexo feminino estão conectadas com a Deusa Mãe denuncia a repetição de uma narrativa que liga coisas e pessoas a funções determinadas, cosendo a explicação com pontos tão apertados que não deixa espaços para que outras relações, outros materiais, outras interpretações possam entrar na discussão. Se por um lado, o trabalho notável de Marija Gimbutas (1982) tornou visível a mulher e lhe concedeu um espaço fulcral no entendimento das sociedades pré-históricas com a interpretação de figuras antropomórficas como Deusa Mãe, por outro lado criou a nomenclatura onde a Arqueologia tradicional vai tecer as suas considerações estereotipadas da mulher: enquanto deusa e enquanto mãe, ligando o sagrado e o profano (BAILEY 2015: 1).

Conimbriga, 54 (2015) 5-25 
Nos estudos mais recentes, a interpretação das figuras antropomórficas distancia-se das cansadas associações de corpos femininos a cultos da fertilidade (e.g. VAlera e Evangelista 2014) evidenciado outras possibilidades interpretativas [sobretudo enquanto "expressões simbólicas ideológicas" (ibid.: 298)], estudando as matérias-primas, outras representações de outros corpos, ditos masculinos, ou prestando atenção ao detalhe (anatómico). Poderíamos também acrescentar que as diferenças físicas não indicam explicitamente diferenças ao nível dos papéis sociais desempenhados por corpos que possuem essas mesmas especificidades físicas. Ser homem ou mulher não permaneceu inalterado ao longo de milénios. A forma como cada grupo lida com as diferenças biológicas dos corpos humanos não é inerente à própria especificidade física.

Alguns autores propõe que a representação do corpo humano se insere num progressivo movimento (que se desenrolará ao longo da Idade do Bronze) da representação individual. Segundo Valera e Evangelista as figuras antropomórficas materializam afirmações ideológicas "num momento de mudanças sociais significantes no sul da Península Ibérica, correspondentes à dissolução do mundo Neolítico e à emergência de novas ordens sociais e ideológicas que marcam o caminho em direção à Idade do Bronze nesta região em particular." (VALERA e EvANGELISTA 2014: 295, tradução da autora). Este movimento parece também materializar-se na arte rupestre (CARDOSO 2007: 439).

A representação humana aparece também inscrita em pequenas estelas, sobretudo em granito, no sítio de Cabeço da Mina, Vila Flor. Até ao momento foram identificadas pouco mais de seis dezenas de estelas (ou fragmentos) das quais cerca de metade se encontra decorada com um conjunto de atributos antropomórficos - olhos, colares, cintos/ faixas - ainda que na maioria dos casos não coincidentes na mesma peça (SANChes 2011). Como é referido por Maria de Jesus Sanches, ainda que as estelas que "evocam a figura humana" tenham sido indexadas a um género (masculino ou feminino) através muitas vezes de indicadores indiretos como cintos ou colares, a autora sublinha: "os géneros, as identidades e os estatutos [...] podem variar não somente ao longo da vida em função de circunstâncias variadas (dádivas, trocas, casamentos, escalão etário, ritos de passagem, etc.), como após a morte (manipulação de cadáveres, partição de cadáveres ou pertences daqueles, etc.) [...] Acresce ainda o facto de em muitos casos o processo de identificação se referir não a indivíduos (tal como os concebemos na socie- 
dade ocidental, moderna e pós-moderna), mas a clãs, grupos etários, etc. (Fowler 2004), sendo estes também considerados "indivíduos". (ibid.: 156). As estelas não representariam entidades individuais e não trazem consigo a possibilidade de identificação do género, pois podem referir-se a grupos (reais ou míticos), ou a entidades (passadas, imaginadas, transformadas).

Também a estela do Caga Cão, Vila Nova de Foz Côa, identificada perto do recinto de Castelo Velho de Freixo de Numão, apresenta uma figura antropomórfica (CARDOSo 2007: 441-442) à qual não foi atribuída nenhuma classificação de género. Esta representação parece estar de acordo com as representações antropomórficas registadas no Vale do Côa (Vale da Casa 11 e Vale dos Namorados 1) onde a figura humana é desenhada esquematicamente, sendo característico uma linha que sai do "tronco" e prolonga o corpo "que pode ser vista como uma cauda, se interpretarmos estas figuras como bovinos, ou falos, se os virmos como humanos." (Luís 2009: 138). Nesta linha, a figura humana pode também conter atributos de outros animais e no desenho se (con)fundir atributos do corpo humano e características de outras coisas (que podem também pertencer ao imaginário destas comunidades). As representações antropomórficas no Vale do Côa durante o Calcolítico Médio e Final caminham numa estilização das figuras como se pode observar na Faia (painel 6), Quinta da Barca (painel 23), Ribeira de Piscos (painel 4 e 10), Vale Videiro e Monte de S. Gabriel (ibid.: 139).

Apesar de se referir à arte paleolítica, Vítor Oliveira Jorge (1997) discutiu já os preconceitos de género e as interpretações anacrónicas que subjazem às explicações tradicionais da arte, denunciando a precariedade de certas interpretações que se referem explicitamente a representações de mulheres e homens nas representações pré-históricas. $\mathrm{O}$ autor refere que "[não é possível] uma visão tradicional, androcêntrica, organizada em dois pólos, opostos e complementares: a do homem caçador, artista, sujeito da acção, e a da mulher reprodutora, venerada nessa sua condição predominantemente passiva, e assim representada na «arte». Esta é um complexo sistema de símbolos que, longe de «reproduzir» o mundo, ajudou a construi-lo; e nesse mundo as relações entre géneros deveriam ser bem mais diversificadas do que, à primeira vista, pareceria. Sem dúvida que pôr em causa uma explicação simples, não significa substitui-la por outra" (ibid.: 41).

As representações antropomórficas parecem acima de tudo repre-

Conimbriga, 54 (2015) 5-25 
sentar seres humanos. Não porque não seja clara a especificação do sexo em algumas das representações, mas porque os papéis que hoje homens e mulheres representam (mesmo questionando as inúmeras possibilidades mais ou menos de acordo com o discurso normativo que nos "ensina" a ser homens e mulheres) não podem ser lidos na Pré-História; já não é possível perpetuar "assunções insuportáveis" (BAILEY 2013: 249). Estas materialidades também não podem ser estudadas sem atender ao seu contexto, sem perceber as relações com as outras coisas com as quais faziam espaço ou denunciavam usos do espaço. São com certeza contadores de histórias. As histórias que se carregam na própria matéria-prima, nos fragmentos, no depósito final, sem descurar a importância da representação do corpo humano, por vezes de forma mais "naturalista", por vezes sugerido por inscrição de motivos oculares ou esquemáticos interpretados como tatuagens ou pinturas faciais. Não podemos descurar também outras representações, por exemplo de animais, os quais podiam também estar ligados/representar seres humanos. É notória a presença de representações de diversos animais em contextos conectados com os recintos peninsulares mas que só agora são alvo de um novo olhar (VALERA 2015). Estas representações foram vistas pela Arqueologia tradicional portuguesa como amuletos de fertilidade (ibid: 16), perpetuando a ligação entre fertilidade e a mulher, a mãe e os atributos biológicos femininos.

\subsection{As pequenas "coisas" e o trabalho doméstico}

"Muitas vezes não fica nada de tangível da vida quotidiana de uma mulher. A comida que cozinhou foi comida; os filhos que cuidou partiram para o mundo." (WoOLF 2014 [1929]: 290)

Virginia Woolf condensou em uma frase a situação da mulher nos últimos séculos da história da Europa ocidental e a materialização da sua condição como mulher, a materialização das tarefas do dia-a-dia, que se confundem com o passar do tempo, com a tradição, e porque de longa diacronia, porque permanentes, asseguram a estabilidade e os próprios objetos que estariam envolvidos nestas tarefas seriam/são pouco visíveis, pouco há a relatar sobre as coisas que as mulheres manipularam diariamente. $\mathrm{O}$ trabalho da mulher na Pré-história decalca o trabalho da mulher do idealizado mundo burguês ocidental, onde "O 
diário trabalho de manutenção das mulheres confunde-se com o passar do tempo." (BARRENo 1996: 9)

A ligação tomada como natural entre mulher e tarefas domésticas foi já discutida por diversos autores, nomeadamente por Sandra Montón-Subías (2010). A autora alerta para o perigo de naturalizar a ligação de certas atividades, sobretudo as tarefas de manutenção, a elementos femininos. Na mesma linha, Almudena Hernando (2010) refere que apesar de a Antropologia fornecer numerosos exemplos que conectam certas funções específicas às mulheres, não existe nada como “atividades puramente femininas ou masculinas"(ibid.: 298). Esta última autora, ao estudar o caso particular de uma tribo brasileira (os Awá) mostra a diversidade de possibilidades de relação entre homens e mulheres e estruturas de poder dentro de uma comunidade.

A atribuição de atividades distintas a homens e mulheres traduz-se nas relações de poder perspetivadas na Pré-história. Mulheres e homens não desempenham apenas funções distintas dentro da comunidade, mas segundo a Arqueologia tradicional, as atividades performatizadas por uns e outros conferem a uns o poder sobre outros. Segundo Margarita Diaz-Andreu (2005), a Arqueologia tradicional sempre atribuiu as tarefas essenciais e determinantes de uma comunidade aos elementos masculinos e as tarefas auxiliares às mulheres. E como Conkey e Spector sublinharam "os elementos masculinos performatizam atividades enquanto os elementos femininos se envolvem em "tarefas", e as descrições das atividades masculinas são mais detalhadas e retratadas como mais ativas e frequentes do que aquelas desempenhadas por mulheres. Existe uma assimetria na visibilidade, níveis de energia, resultados, e contribuições de ambos os sexos" (Conkey e Spector 1984: 10, citado em Gero 1985: 344; tradução da autora)

Como referimos, os papéis dados pela Arqueologia tradicional à mulher no passado relacionar-se-iam com o espaço doméstico, com tarefas que se confundem com o passar do tempo, com a vida quotidiana, da qual muitas vezes não fica nada de tangivel. Os objetos ligados a estas tarefas apontariam para a permanência, para formas estáveis, sobretudo se atendermos a conjuntos cerâmicos (tipos de formas e de organizações decorativas), ou por exemplo a moinhos manuais (moventes e dormentes sobretudo em granito). Estas atividades desenrolar-se-iam no espaço doméstico, dentro de casa ou em redor da unidade familiar mas geralmente intramuros. Os objetos que 
denunciam mudanças tecnológicas ou que indicam transformações nos processos socioeconómicos são normalmente associadas a elementos masculinos (metais, utensilagem lítica associada sobretudo à caça, à guerra e à prática da agricultura).

$\mathrm{Na}$ tradição arqueológica o objeto é tido como a materialização de significados impressos no material pelo ser humano. Os objetos são encarados como meios de estudo para a compreensão de sociedades e culturas passadas, para tentar alcançar o protagonista por detrás do artefacto (OLSEN 2010: 23-24). E é só a crença nesta possibilidade, a de alcançar o criador, o autor dos artefactos, exumados no presente, ou os agentes que os usaram no passado, que permite à Arqueologia desenhar mulheres ou homens por detrás dos materiais arqueológicos. Dito por outras palavras, é a crença na capacidade da Arqueologia, através da análise dos materiais, em revelar intencionalidades e significados outrora impressos nos materiais, que permite a revelação de protagonistas passados. E é também a ligação (que se admite como natural) entre forma e função. A determinada forma (de recipiente cerâmico, de estrutura, de sítio) corresponde uma função. O objeto, no qual foi impressa a sua funcionalidade através da moldagem da matéria numa determinada forma, entra num conjunto específico de atividades: tecelagem, preparação de alimentos, caça, guerra... Estas atividades, segundo a Arqueologia tradicional, seriam performatizadas por um dos sexos.

\section{As Mulheres e a construção da Pré-História}

É possível e desejável projetar na Pré-história o ser-se mulher dos últimos séculos da História Europeia? Como definir "mulher"? Pelo conjunto de características físicas? Por um conjunto de aptidões, atitudes e representações?

Judith Butler (1990) alertou para o facto de, no mundo ocidental moderno, o género se basear na materialidade do corpo, no sexo biológico. No entanto, segundo a autora, não existe matéria a priori fora do discurso. O sexo, na linha de Butler, é a materialização de um ideal regulatório heterossexual, ligado a processos de controlo e poder. A autora defende que o género é socialmente construído e opera através de complexas relações que são definidas pela interação de cada um e de todos com o mundo em que habita. Não se trata apenas das ações que 
cada um protagoniza, mas sim a rede de relações em que cada um está inserido, de forma consciente ou não. O género constrói-se também pelas expressões discursivas que enunciamos, muitas vezes como apenas descritivas mas que atuam como performativas na medida em que nos inscrevem (e aos outros) numa gramática discursiva. Assim, a frase "eu sou uma mulher" não é apenas descritiva mas insere-se num mundo discursivo e "normaliza" a condição de mulher. Pela repetição dos atos performativos que se constroem em rede e em relação com o outro, ser-se mulher é naturalizado.

No entanto, segundo o arqueológo norueguês Olsen (2010), Butler apenas se ocupa do corpo humano, da matéria que somos, esquecendo os outros materiais que também se conjugam na materialização do que é ser-se mulher e homem. A Pré-história fala acerca de homens e mulheres através das coisas, de objetos, que materializam os dois géneros e permitem, segundo a Arqueologia tradicional, definir homem e mulher. Provavelmente, nos processos de naturalização ou constituição dos géneros devemos, também, equacionar de que forma a ciência ocidental e em particular a Arqueologia permitiu a associação entre materiais, artefactos e a definição de géneros.

Apenas a mulher passa (ou pode passar) pela experiência da maternidade. A mulher experiencia a gravidez, o parto e (em muitos casos) o período de amamentação do bebé. Se estas experiências lhe são exclusivas, a forma como as experiencia é cultural e socialmente construída (e a própria maternidade não pode ser tida como definição do ser-se mulher). As mulheres surgem-nos na leitura do registo arqueológico encaixadas em formas tipológicas que as relacionam com atividades específicas e entendidas como mães. Nunca é questionada a ambiguidade ou as inúmeras variações do ser-se mulher e nunca é questionada a projeção no passado de tarefas que o modelo patriarcal de organização social associou às mulheres no mundo moderno ocidental. Claro que não negamos a existência de mulheres (ou de seres que partilhavam um corpo muito semelhante ao meu) a tecer, a moer ou na confecção de refeições, mas terão sido muito mais, e o inquérito tradicional parece esgotar-se em si mesmo. Por que é que tentamos dotar uma atividade ou função de género? Será importante no nosso trabalho ou mesmo válida essa tentativa? No entanto, as mulheres foram colocadas no espaço da casa durante a Pré-história por discursos arqueológicos androcêntricos e aí permaneceram, dentro da casa, ao longo de vários séculos na Europa Ocidental, mas tal como refere Virgina Woolf "todas as paredes 
contêm o seu poder criativo que nem os tijolos ou cimento conseguiram refrear." (WoOLF 1996 [1929]: 105).

Apesar da escassez de textos no contexto da Arqueologia Pré-histórica portuguesa que problematizam este tópico, é notável a presença atual de mulheres arqueólogas em Portugal assim como o seu empenho e ligação a inúmeros projetos de investigação. Neste sentido, é curioso o silêncio dentro da disciplina acerca dos explícitos discursos androcêntricos que permeiam a maioria dos textos em português acerca do passado e a não existência deste tópico nos curricula de nenhum curso de Arqueologia em Portugal (salientado por Jorge e Jorge 1996 e como já tivemos oportunidade de discutir, VALE 2010). Este facto pode dever-se à situação vivida em Portugal durante o Estado Novo (e.g. AMÂNCIo 2003, Gomes 2008), à entrada tardia das "ideias feministas" e a curta existência das Ciências Sociais em Portugal, preocupadas sobretudo em discutir temas relacionados com as desigualdades sociais (AmÂNCIO 1998). No entanto, em Espanha, são numerosas as publicações em Arqueologia que questionam a invisibilidade da mulher nos discursos sobre o passado, que valorizam as atividades de manutenção (que seriam desenvolvidas segundo algumas autoras por mulheres) e que denunciam a construção androcêntrica do passado (DiÁz-ANDREU e Monton-Subias 2012).

Será possível escrever na ausência de género? Que perigos implicaria a ausência das múltiplas vozes mais ou menos femininas, mais ou menos masculinas? Conscientes da impossibilidade de um discurso neutro, é necessário trazer à luz os preconceitos possíveis de apontar, na linha de Irigaray (2007: 22-30). Bauman (2005: 22) sublinhou a fragilidade e a condição provisória da identidade. Contudo, a Arqueologia ainda pede "Clareza, objectividade, e redução (dos problemas) a leis ou termos matemáticos" (Thomas 2004: 247). No mundo moderno, com a sua obsessão de tudo classificar para tudo incluir (ver FouCAULt 1994 [1976]), também as comunidades pré-históricas são indexadas para que se tornem parte do arquivo moderno e este cumpra a tarefa da modernidade: a ordem (BAUMAn 2007: 16).

Provavelmente os indivíduos do passado deveriam ser encarados apenas como seres humanos. Yourcenar (1981) afirmou que uma mulher é primeiramente um ser humano; Virginia Woolf quando se pergunta "o que é uma mulher?" diz "- Garanto-lhes que não sei" (2014 [1931]: 194) e no seu texto preparatório para a comunicação que apresentou em 1929 intitulada "As mulheres e a ficção", quando pensa 
na comunidade, naqueles que a rodeiam enquanto tece um conjunto de considerações acerca do papel da mulher diz "Todos os seres humanos estavam a dormir - deitados horizontalmente, surdos a tudo" (1996 [1931]: 37). - Virginia Woolf não se refere a homens e mulheres mas quando pensa nos outros que dormem no mesmo espaço que é a cidade diz seres humanos.

\section{Conclusão}

Os estudos feministas vieram chamar à atenção para a invisibilidade da mulher nos discursos do passado e iniciaram a escrita de outros cenários onde a mulher se encontra presente. Os estudos de género vieram pôr em causa a definição de mulher e de homem e sublinharam o facto de ser-se mulher ou homem estar enraizado em práticas performativas e discursivas. Enquanto tomarmos como certo a definição de mulher qualquer discussão à volta da sua importância na Pré-história será em vão. Como referimos, pensamos que a busca de homens e mulheres na Pré-história não escapará à forma como cada um se vê, como cada um constrói as definições de homem e mulher. O problema reside na representação.

A Arqueologia tradicional em Portugal representou a mulher como deusa, ligando o seu corpo ao sagrado, considerando os seus atributos físicos objetos de culto, e também a mulher como mãe, ligando o seu dia-a-dia à casa, ao espaço doméstico. Estas duas dimensões encontram a sua justificação nas representações antropomórficas, assim como na próprias características físicas dos corpos do sexo feminino. No entanto, leituras recentes das representações antropomórficas, assim como estudos acerca da complexa construção de géneros e sua articulação com especificidades biológicas parecem apontar para a incapacidade da Arqueologia em desenhar homens e mulheres na Pré-história, tal como (n)os entendemos hoje, e alertam para o perigo da Arqueologia validar/naturalizar discursos androcêntricos, que procuram a justificação/origem dos papéis desempenhados hoje por uns e por outros no passado.

Concluímos com as representações de um arqueólogo/ artista britânico, Aaron Watson (2008). O autor não desenha homens e mulheres mas corpos humanos. Seres humanos que questionam a estranheza dos sítios arqueológicos hoje, que potenciam as questões, que se mexem 
ao ritmo da irrequietude dos arqueológos e do grande público. E são estas as imagens possíveis: de seres humanos. De seres humanos que não resistem à estranheza, pois aí reside a própria possibilidade interpretativa. As imagens de Aaron Watson não são cópias do imaginário ocidental burguês e podem subverter as representações da mulher como mãe e deusa, e do homem como o agricultor, guerreiro ou caçador... As imagens prenhes de cor de Aaron Watson pensam uma área geográfica especifica, Kilmartin, no sudoeste da Escócia, onde um conjunto de menires pontuam a paisagem, e têm como objectivo "ser inspiradoras e teatrais, evocando movimento, energia e experiências multissensoriais (...) desencorajando que sejam consumidas como representações verdadeiras. Ao contrário, o seu tamanho e as cores vigorosas estimulam os espetadores a participarem ativamente, dando sentido aos elementos estranhos e disruptivos." (ibid: 159).

As histórias que contamos são assinadas por nós, carregam o nosso nome e desta forma as interpretações/representações arqueológicas que construímos são histórias prenhes de nós. É necessário fazer "descer a matéria à vida de quem conta, para a fazer emergir de novo, a partir dele. Desde modo, a marca própria de quem conta é detectável na história narrada, tal como a marca do oleiro no vaso de barro." (BENJAMIN 2015: 157-158). Herdamos uma história que passamos a quem sabe ouvir e este, como herdeiro, contará a sua história. É herança partilhada, tecida no trabalho das mãos, na experiência; a história que o arqueólogo conta traz consigo a experiência das suas mãos e é sobretudo no trabalho de escavação que essa história é contada e partilhada. Falar de seres humanos que nos antecederam é também descrever as relações entre "coisas" antes de as indexar numa tabela classificatória e explicativa. É o olhar atento às relações, ao detalhe, que possibilitam a tradução, não como cópia de um original imaginado e ansiado, mas como interpretação do que ainda é, e que nos permitem falar de outros seres humanos.

Agradecimentos: Muito obrigada a Joana Alves Ferreira e Sérgio Gomes pelas inúmeras conversas acerca do tema e a Lídia Baptista pelas importantes indicações bibliográficas. Expressamos também o nosso agradecimento a Ana Cristina Martins pelo convite para participar no Seminário "A Arqueologia Portuguesa sob o Signo da Mulher". Este artigo insere-se num projecto de pós-doutoramento financiado pelo FCT.

Conimbriga, 54 (2015) 5-25 


\section{BIBLIOGRAFIA}

Almeida, Miguel Vale (2003) - Antropologia e sexualidade. Consensos e conflitos teóricos em perspectiva histórica. In SoAres e J. M. VAz, J. M. (eds.), Sexologia, Perspectiva Multidisciplinar. Coimbra: Quarteto, vol. II, p. 53-72.

AmÂNCIO, Lígia (1998) - O feminismo português no final do século XX. Um olhar sobre o passado ausente e a promessa de futuro. In Movimento Feminista em Portugal. Seminário organizado pela UMAR (5 e 6 de Dezembro de 1998). Lisboa, p.7682. umar.no.sapo.pt/investigacao/.../Semin\%E1rio_Mov.Feminista.pdf

AmÂNcio, Lígia (2003) - O género no discurso das ciências sociais. Análise Social 168, p. $687-714$.

Bailey, Douglass (2013) - Figurines, Corporeality, and the Origins of the Gendered Body. In Bolger, Diana (ed.), A Companion to Gender Prehistory. John Wiley \& Sons. Inc., p. 244-264.

Bailey, Douglass (2015) - Figurines: Europe. In Wheleham, Patricia e Bolien, Anne (eds.), The International Encyclopedia of Human Sexuality. John Wiley \& Sons. Inc., p. 1-3.

Baptista, Lídia (2015) - Contextos de inumação em "fossa" da Pré-história Recente no Interior Alentejano - contributos para o conhecimento das práticas de enterramento. Atas do VII Encontro de Arqueologia do Sudoeste Peninsular. [Aroche 2013], p. 29-62.

Barreno, Maria Isabel (1996) - Prefácio. In Virginia Woolf. Um Quarto que Seja Seu. Lisboa: Vega, p. 7-13.

Bauman, Zigmund (2007 [1991]) - Modernidade e Ambivalência. Lisboa: Relógio D'Água.

Benjamin, Walter (2015) - O contador de Histórias. Reflexões sobre a Obra de Nikolai Leskov. Linguagem $\mid$ Tradução| Literatura (filosofia, teoria e crítica). Edição e tradução de João Barrento. Assírio e Alvim, p. 147-178.

Bourdieu, Pierre (2013) - A Dominação Masculina. Santa Maria da Feira: Relógio D'Água Editores.

ButLer, Judith (1990) - Gender Trouble. Feminism and the Subversion of Identity. New York. London: Routledge.

Cardoso, João Luís (1995) - Os Ídolos Falange do Povoado Pré-Histórico de Leceia (Oeiras). Estudo Comparado. Estudos Arqueológicos de Oeiras 5. Oeiras: Câmara Municipal, p. 213-232.

Cardoso, João Muralha (2007) - Castanheiro do Vento (Horta do Douro, Vila Nova de Foz Côa - Um Recinto Monumental do III e II milénio a.C.: Problemática do Sítio e das suas Estruturas à Escala Regional. Dissertação de doutoramento. Faculdade de Letras da Universidade do Porto. Edição policopiada.

Cirne, Joana e Henriques, Marília (2012) - Viagem pela História 7. Areal Editores.

Conkey, M. e Spector, J. (1984) - Archaeology and the study of gender. In SCHIFFER, M. (ed.), Advances in Archaeological Method and Theory 7. New York: Academic Press, p. 1-38.

Conimbriga, 54 (2015) 5-25 
DíAZ-Andreu, Margarita (2005) - Género y Arqueología: una nueva síntesis. In SÁnchez Romero, M. (ed.), Arqueología y Género. Granada: Universidad de Granada, p. 13-51.

DíAZ-Andreu, Margarita e Montón-SubÍAs, Sandra (2012) - Gender and Feminis min Prehistoric Archaeology of Southwest Europe: Spanish, Portuguese and French prehistoric archaeologies. In Bolger, D. L. (ed.), The Companion to Gender Prehistory. Oxford: Wiley-Blackwell, p. 438-457.

Foucault, Michel (1994 [1976]) - História da Sexualidade I. A Vontade de Saber. Lisboa: Antropos. Relógio D’Água.

Fowler, Chris (2004) - The Archaeology of Personhood. An Anthropological Approach. Londres: Routledge.

Gero, J. (1985) - Socio-politics and the woman-at-home ideology. American Antiquity, 50 (2), p. 342-350.

Gimbutas, Marija (1982) - Goddesses and Gods of Old Europe: Myths and Cult Images. Londres: Thames \& Hudson.

Gomes, Sérgio (2008) - Manuela Delgado and Jorge Alarcão in the history of archaeology in Portugal. [comunicação apresentada na sessão "Personality in the history of archaeology". Theoretical Archaeology Group (TAG). Southampton. UK. 15-17 dezembro 2008].

GonçalVes, Victor (2004) - Manifestações do Sagrado na Pré-história do Ocidente Peninsular 5. O explícito e o implícito. Breve dissertação, invocando os limites fluidos do figurativo, a propósito do significado das placas de xisto gravadas do terceiro milénio a.n.e. Revista Portuguesa de Arqueologia 7, p. 166-183.

Hernando, Almudena (2010) - Gender, Individuality, and Affine/Consanguineal Relationships in Egalitarian Societies: The Awá-Guajá Case. In Dommasnes, L., Huorungdal, T., Mónton-Subías, S., Sánchez Romero, M. e Wicker, N. (eds.), Situating Gender in European Archaeologies. Archaeolingua. Budapeste, p. 283-306.

HernANDo, Almudena (2013) - Change, individuality and reason, or how Archaeology has legitimized a patriarchal modernity. In González-Ruibal, A. (ed.), Reclaiming Archaeology. Beyond the tropes of Modernity. London: Routledge, p. $155-167$.

IrIGARAY, Lucy (2007) - Je, Tu, Nous. Toward a culture of difference. London: Routledge Classics.

Jordanova. Ludmilla (1989) - Sexual Visions. Images of Gender in Science and Medicine between the Eighteenth and Twentieth Centuries. Madison: The University of Wisconsin Press.

JoRge, Susana Oliveira (2014) - Enclosures and Funerary Practices. About an Archaeology in Search for the Symbolic Dimension of Social Relations. In VAlerA, António Carlos (ed.), Recent Prehistoric Enclosures and Funerary Practices in Europe. Oxford: BAR International Series 2676, p. 71-82.

Jorge, Susana Oliveira; Oliveira Maria de Lurdes, Nunes, Susana A. e Gomes, Sérgio Rocha (1998-1999) - Uma Estrutura Ritual com Ossos Humanos no Sítio

Conimbriga, 54 (2015) 5-25 
Pré-Histórico de Castelo Velho de Freixo de Numão (V $V^{\mathrm{a}}$. N ${ }^{\mathrm{a}}$. de Foz Côa). Portugália. Nova série. XIX-XX, p. 29-70.

Jorge, Vítor Oliveira (1997) - Ideias Prévias a uma Pré-História do Género. Actas dos $3^{\circ}$ Cursos Internacionais de Verão de Cascais (1 a 6 de Julho de 1996). Cascais: Câmara Municipal de Cascais. I, p. 21-42.

Jorge, Vítor Oliveira e Jorge, Susana Oliveira (1996) - Women in Portuguese Archaeology. Trabalhos de Antropologia e Etnologia 36. SPAE. Porto, p. 159-167.

Kunst, Michael; Cardoso, João Luís e Waterman, Anna (2014) - Human Bones from Chalcolithic Walled Enclosures of Portuguese Estremadura: The Examples of Zambujal and Leceia. In Valera, António Carlos (ed.), Recent Prehistoric Enclosures and Funerary Practices in Europe. Oxford: BAR International Series 2676, p. 83-98.

Luís, Luís (2009) - Rock Art as Land Art. A Diachronic View of the Côa Valley (NE Portugal) Post-Paleolithic Rock Art. In Balbín Behrmann, Rodrigo, Bueno Ramirez, Primitiva, González Antón, Rafael e Arco Aguilar, Carmen (eds.), Grabados Rupestres de la Fachada Atlântica Europea y Africana/ Rock Carvings of the European and African Atlantic and African Atlantic Façade. Oxford: BAR International Series 2043, p. 129-147.

Montón-Subías, Sandra (2010) - Maintenace Activities and the Ethics of Care. In Dommasnes, L., Huorungdal, T., Mónton-Subías, S., Sánchez Romero, M. e Wicker, N. (eds.), Situating Gender in European Archaeologies. Archaeolingua. Budapeste, p. 35-50.

Olsen, Bjornar (2010) - In Defense of Things: Archaeology and the Ontology of Objects. Plymouth: Altamira Press.

SAnches, Maria de Jesus (2011) - As Estelas antropomórficas de Picote - Mirando do Douro (Trás-os-Montes). In VilaçA, Raquel (coord.), Estelas e estátuas-menires da Pré à Proto-história. [Actas IV Jornadas Raianas]. Sabugal, p. 143-174.

Thomas, Julian (2004) - Archaeology and Modernity. Londres: Routledge.

Vale, Ana (2010) - Translating Materials into Activities and Activities into Persons: The Persistence of Gender Prejudices in Past Narratives in the Iberian Peninsula. In Dommasnes, L., Huorungdal, T., Mónton-Subías, S., SÁnchez Romero, M. e Wicker, N. (eds.), Situating Gender in European Archaeologies, Archaeolingua, Budapeste, p. 137-153.

Valera, António Carlos (2014) - O Conjunto de Materiais Votivos do Contexto Funerário do Recinto 1 de Bela Vista 5 (Mombeja, Beja). In VALERA, António Carlos (coord.), Bela Vista 5. Um Recinto do Final do $3^{\circ}$ milénio a.n.e. (Bombeja, Beja). Lisboa: Era Monográfica, p. 41-45.

VAlera, António Carlos (2015) - Ídolos Falange, Cervídeos e Equídeos. Dados e Problemas a partir dos Perdigões. Apontamentos de Arqueologia e Património 10. Lisboa: NIA-ERA, p. 6-20.

Valera, António Carlos e Evangelista, Lucy Shaw (2014) -Anthropomorphic Figurines at Perdigões Enclosure: Naturalism, Body Propostion and Canonical

Conimbriga, 54 (2015) 5-25 
Posture as Forms of Ideological Languague. European Journal of Archaeology 17 (2), p. 286-300.

Valera, António Carlos; Evangelista, Lucy Shaw \& Castanheira, Patrícia (2014) "Zoomorphic Figurines and the Problem of the Human-Animal Relantionship in the Neolithic and Calcolithic Southwest Iberia." Menga. Revista de Prehistoria de Andalucía 05, p. 15-41.

Valera, António Carlos, Silva, Ana Maria, Cunha, Claudia, Evangelista, Lucy Shaw (2014) - Funerary Practices and Body Manipulation at Neolithic and Chalcolitic Perdigões Ditched Enclosure (South Portugal). In VaLera, António Carlos (ed.), Recent Prehistoric Enclosures and Funerary Practices in Europe, Oxford: BAR International Series 2676, p. 37-57.

Watson, Aaron (2008) - Learning to see through the "Kilmartin Eye". In Thomas, Julian e Jorge, Vitor Oliveira (eds.), Archaeology and the Politics of the Vision in a Post-Modern Context. Cambridge: Cambridge Scholars Publishing, p. 147-162.

Woolf, Virginia (2014 [1929]) - As Mulheres e a Ficção. Ensaios Escolhidos. Tradução Ana Maria Chaves. Relógio D’Água Editores, p. 284-293.

Woolf, Virginia (2014 [1931]) - Profissões para Mulheres. Ensaios Escolhidos. Tradução Ana Maria Chaves. Relógio D’Água Editores, p. 191-196.

Woolf, Virginia (1996 [1929]) - Um Quarto que Seja Seu. Lisboa: Vega.

Yourcenar, Margueritte (1991) - La condition feminine, disponível em: http://www. youtube.com/watch?v=F0N3EofaqkM (última consulta: 1 de dezembro de 2015).

Conimbriga, 54 (2015) 5-25 